\title{
Patterns of Metastasis in Merkel Cell Carcinoma
}

\author{
Yun Song, MD, Feredun S. Azari, MD, Rebecca Tang, BA, Adrienne B. Shannon, MD, John T. Miura, MD, \\ Douglas L. Fraker, MD, and Giorgos C. Karakousis, MD
}

Department of Surgery, University of Pennsylvania Perelman School of Medicine, Philadelphia, PA

\begin{abstract}
Background. Merkel cell carcinoma (MCC) is a cutaneous neuroendocrine malignancy with a propensity for regional and distant spread. Because of the relative infrequency of this disease, the patterns of metastasis in MCC are understudied.

Methods. Patients with American Joint Committee on Cancer (8th edition) stage I-IV MCC treated at our institution were identified (1/1/2008-2/28/2018). The first site of metastasis was classified as regional [regional lymph node (LN) basin, in-transit] or distant. Distant metastasisfree (DMFS) and MCC-specific (MSS) survival were estimated.

Results. Of 133 patients, 64 (48\%) had stage I, 13 (10\%) stage II, $48(36 \%)$ stage III, and $8(6 \%)$ stage IV disease at presentation. The median follow-up time in patients who remained alive was 36 (interquartile range 20-66) months. Regional or distant metastases developed in 78 (59\%) patients. The first site was regional in $87 \%$, including $73 \%$ with isolated LN involvement, and distant in $13 \%$. Thirtyseven (28\%) patients eventually developed distant disease, which most commonly involved the abdominal viscera $(51 \%)$ and distant LNs (46\%) first. The lung $(0 \%)$ and brain (3\%) were rarely the first distant sites. Stage III MCC at presentation was significantly associated with worse DMFS (hazard ratio $4.87, P=0.001$ ) and stage IV disease with worse MSS (hazard ratio 6.30, $P=0.002$ ).
\end{abstract}

Meeting presentation: Accepted for poster presentation at the 2020 Society of Surgical Oncology International Conference on Surgical Cancer Care (not presented because of COVID-19 pandemic).

(C) Society of Surgical Oncology 2020

First Received: 22 January 2020;

Published Online: 13 May 2020

Y. Song, MD

e-mail: yun.song@uphs.upenn.edu
Conclusions. Regional LN metastasis is the most common first metastatic event in MCC, confirming the importance of nodal evaluation. Distant disease spread appears to have a predilection for certain sites. Understanding these patterns could help to guide surveillance strategies.

Merkel cell carcinoma (MCC) is an aggressive neuroendocrine cutaneous malignancy, which was first described by Toker. ${ }^{1}$ It often presents in sun-exposed areas as a rapidly growing, firm, nontender nodule and has been associated with immunosuppression, comorbid malignancies, exposure to ultraviolet radiation, and infection by the Merkel cell polyomavirus. ${ }^{2-4}$ Although its incidence has been rising in recent years, it remains a relatively rare malignancy, with only approximately 2500 cases diagnosed per year in the United States. ${ }^{5}$ MCC is known to have a propensity for regional and distant metastasis and has been associated with a high mortality rate, with estimated 5-year overall survival rates of $14-51 \%$ depending on the extent of disease at presentation. ${ }^{6}$

The current approach to staging for MCC includes primary tumor biopsy, complete skin and regional lymph node (LN) examination, and consideration of cross-sectional imaging for metastatic screening. ${ }^{7}$ Because of frequent regional LN involvement, sentinel lymph node biopsy (SLNB) is generally recommended for patients with clinically localized MCC, although a survival benefit has not been clearly demonstrated. ${ }^{7-11}$ Distant metastasis also occurs frequently; institutional series demonstrate that approximately one-third of patients with MCC will eventually develop distant disease. ${ }^{12,13}$ However, because of the relative infrequency of this disease, the timing and frequencies of regional and distant disease spread have not been well characterized, resulting in relatively vague baseline and surveillance imaging recommendations. The National Comprehensive Cancer Network guidelines propose that baseline imaging with computed tomography 
(CT) or whole-body positron emission tomography with fused CT (PET/CT) may be useful for MCC, especially in the setting of LN-positive disease. ${ }^{7}$ On follow-up, guidelines recommend consideration of imaging as clinically indicated.

The purpose of the current study was to describe the patterns of regional and distant metastasis in 133 patients treated for MCC at our institution. The frequencies of the first sites of metastasis and time to distant metastasis were determined. A better understanding of these patterns of disease spread may help to guide imaging and disease surveillance strategies.

\section{METHODS}

Approval for this study was obtained from the institutional review board of the University of Pennsylvania. Consecutive adult patients age 18 years or older who were treated at our institution for biopsy-proven MCC diagnosed between January 1, 2008 through February 28, 2018 were identified. One patient was excluded for insufficient clinical information and loss to follow-up. The final study cohort consisted of 133 patients.

Disease stage at presentation was categorized according to the American Joint Committee on Cancer (AJCC) 8th edition staging system. ${ }^{6,14}$ Pathologic staging was used for patients with clinically localized MCC (no evidence of regional or distant metastases at presentation) who underwent SLNB. If a SLNB was not performed, patients were clinically staged. Patient characteristics recorded included age at initial diagnosis, sex, history of other malignancies, and immunosuppression. Immunosuppression was defined as having a solid organ transplant, bone marrow transplant, hematologic malignancy, autoimmune disorder, human immunodeficiency virus/acquired immunodeficiency syndrome, or receipt of chemotherapy within the 3 months before MCC diagnosis. Primary tumor characteristics analyzed included location, diameter, and presence of lymphovascular invasion. Baseline imaging, including ultrasound, CT, and PET/CT, was defined as imaging performed within 1 month of MCC diagnosis. The frequency and modality of follow-up surveillance imaging was at the discretion of treating providers. Treatment characteristics recorded included primary tumor excision, SLNB, complete lymph node dissection, and adjuvant or first-line radiation and systemic therapies.

The primary outcome was the first site of metastasis, categorized as regional (regional LN basin and in-transit disease) or distant (distant LNs, distant soft tissue, and other organs). The secondary outcomes were the first site(s) of distant metastasis, distant metastasis-free survival (DMFS), and MCC-specific survival (MSS). DMFS was estimated in patients who presented with stage I through III MCC and defined as the number of months from MCC presentation to diagnosis of first distant metastasis, censoring at last follow-up for those without distant disease. MSS was defined as the interval, in months, from initial diagnosis to MCC-related death. Patients who were alive or died of other causes were censored at last follow-up.

Categorical variables are presented as frequencies and continuous variables as medians with interquartile ranges (IQR). Univariate comparisons were made using the Pearson's Chi squared or Fisher's exact test, as appropriate, for categorical variables, and the Wilcoxon rank-sum test for continuous variables. Survival curves were estimated using the Kaplan-Meier method and compared using the log-rank test. Associations with DMFS and MSS were determined using Cox regression. Multivariable Cox proportional hazards models included factors with $P<0.10$ by univariate analyses with sequential removal of variables with $P>0.10$ on multivariable regressions. All tests were two-sided. $P$ values $<0.05$ were considered statistically significant. Statistical analyses were performed using $\mathrm{R}$ version 3.5.3. ${ }^{15}$

\section{RESULTS}

\section{Baseline Characteristics}

A total of 133 patients met study criteria, including 64 (48\%) with stage I, 13 (10\%) with stage II, 48 (36\%) with stage III, and $8(6 \%)$ with stage IV MCC at presentation (Table 1). The median age was 74 (IQR 66-82) years, and a majority $(61 \%)$ of patients were male. Immunosuppression was present in $14 \%$ of patients overall and up to $39 \%$ of those with stage II MCC. The most common primary tumor location was the head and neck in $41 \%$ of patients.

Definitive excision of the primary tumor was not performed in $22(16 \%)$ patients. Fourteen of these patients presented with clinical stage III MCC, which represented $45 \%$ of those with clinical stage III disease. All eight patients who presented with stage IV MCC also did not undergo primary tumor resection. When the primary tumor was excised and margin was reported, $>1.0-2.0 \mathrm{~cm}$ represented a plurality $(31 \%)$ of margins utilized.

Among 94 patients who presented with clinically localized disease, 68 (72\%) underwent SLNB. SLNB was also performed for one patient with evidence of in-transit disease at presentation. Among the 69 patients who underwent SLNB, 17 (25\%) were positive. Twenty $(21 \%)$ patients with clinically localized MCC did not undergo SLNB, and SLNB failed in another $6(6 \%)$ patients. These patients were clinically staged as stage I/II. Among those with stage III MCC, 31 (65\%) presented with clinically 
TABLE 1 Characteristics of patients diagnosed with Merkel cell carcinoma

\begin{tabular}{|c|c|c|c|c|c|}
\hline \multirow[t]{3}{*}{ Characteristics } & \multicolumn{5}{|l|}{$N(\%)$} \\
\hline & \multirow{2}{*}{$\begin{array}{l}\text { All patients } \\
N=133\end{array}$} & \multicolumn{4}{|c|}{ AJCC 8th edition stage at presentation } \\
\hline & & $\begin{array}{l}\text { Stage I } N=64 \\
(48 \%)\end{array}$ & $\begin{array}{l}\text { Stage II } N=13 \\
(10 \%)\end{array}$ & $\begin{array}{l}\text { Stage III } N=48 \\
(36 \%)\end{array}$ & $\begin{array}{l}\text { Stage IV } N=8 \\
(6 \%)\end{array}$ \\
\hline \multicolumn{6}{|l|}{ Demographics } \\
\hline Age in years, median (IQR) & $74(66-82)$ & $76(65-82)$ & $77(73-84)$ & $71(64-80)$ & $70(69-73)$ \\
\hline \multicolumn{6}{|l|}{ Sex } \\
\hline Female & $52(39)$ & $31(48)$ & $4(31)$ & $15(31)$ & $2(25)$ \\
\hline Male & $81(61)$ & $33(52)$ & $9(69)$ & $33(69)$ & $6(75)$ \\
\hline \multicolumn{6}{|l|}{ Race } \\
\hline White & $119(89)$ & $57(89)$ & $11(85)$ & $43(90)$ & $8(100)$ \\
\hline Non-White & $14(11)$ & $7(11)$ & $2(15)$ & $5(10)$ & $0(0)$ \\
\hline Immunosuppression & $18(14)$ & $4(6)$ & $5(38)$ & $7(15)$ & $2(25)$ \\
\hline History of other malignancies & $35(26)$ & $20(31)$ & $6(46)$ & $9(19)$ & $0(0)$ \\
\hline \multicolumn{6}{|l|}{ Primary tumor characteristics } \\
\hline \multicolumn{6}{|l|}{ Location } \\
\hline Head/neck & $54(41)$ & $27(42)$ & $6(46)$ & $20(42)$ & $1(12)$ \\
\hline Upper extremity & $28(21)$ & $19(30)$ & $3(23)$ & $6(12)$ & $0(0)$ \\
\hline Lower extremity & $26(20)$ & $11(17)$ & $4(31)$ & $9(19)$ & $2(25)$ \\
\hline Trunk & $12(9)$ & $7(11)$ & $0(0)$ & $4(8)$ & $1(12)$ \\
\hline Unknown primary & $13(10)$ & $0(0)$ & $0(0)$ & $9(19)$ & $4(50)$ \\
\hline Diameter in cm, median (IQR) & $1.2(0.7-2.1)$ & $0.9(0.5-1.4)$ & $2.4(2.2-2.9)$ & $2.5(1.2-4.0)$ & $2.1(2.0-2.2)$ \\
\hline Depth in mm, median (IQR) & $6.0(3.3-11.0)$ & $5.0(3.0-8.0)$ & $8.0(7.5-11.5)$ & $8.5(5.8-15.5)$ & $17.0(14.5-19.5)$ \\
\hline \multicolumn{6}{|l|}{ Lymphovascular invasion } \\
\hline Absent & $44(33)$ & $28(44)$ & $5(39)$ & $11(23)$ & $0(0)$ \\
\hline Present & $41(31)$ & $19(30)$ & $6(46)$ & $14(29)$ & $2(25)$ \\
\hline Unknown primary/not reported & $48(36)$ & $17(27)$ & $2(15)$ & $23(48)$ & $6(75)$ \\
\hline \multicolumn{6}{|l|}{ Initial workup and treatment } \\
\hline \multicolumn{6}{|l|}{ Baseline imaging } \\
\hline None & $14(11)$ & $10(16)$ & $2(15)$ & $2(4)$ & $0(0)$ \\
\hline Ultrasound & $2(2)$ & $2(3)$ & $0(0)$ & $0(0)$ & $0(0)$ \\
\hline $\mathrm{CT}$ & $27(20)$ & $17(27)$ & $1(8)$ & $8(17)$ & $1(12)$ \\
\hline PET/CT & $90(68)$ & $35(55)$ & $10(77)$ & $38(79)$ & 7 (88) \\
\hline $\begin{array}{l}\text { Definitive excision of primary } \\
\text { tumor }\end{array}$ & $111(84)$ & $64(100)$ & 13 (100) & $34(71)$ & $0(0)$ \\
\hline \multicolumn{6}{|l|}{$\begin{array}{l}\text { Primary tumor excision margin } \\
(\mathrm{cm})\end{array}$} \\
\hline No excision & $22(16)$ & $0(0)$ & $0(0)$ & $14(29)$ & $8(100)$ \\
\hline$\leq 0.5$ & $22(16)$ & $13(20)$ & $3(23)$ & $6(12)$ & $0(0)$ \\
\hline$>0.5-1.0$ & $20(15)$ & $11(17)$ & $4(31)$ & $5(10)$ & $0(0)$ \\
\hline$>1.0-2.0$ & $41(31)$ & $26(41)$ & $3(23)$ & $12(25)$ & $0(0)$ \\
\hline$>2.0$ & $3(2)$ & $1(2)$ & $1(8)$ & $1(2)$ & $0(0)$ \\
\hline Not reported & 25 (19) & $13(20)$ & $2(15)$ & $10(21)$ & $0(0)$ \\
\hline \multicolumn{6}{|l|}{ SLNB } \\
\hline Not performed & $58(44)$ & $15(23)$ & $5(38)$ & $30(62)^{\mathrm{a}}$ & $8(100)$ \\
\hline Performed & $69(52)$ & $44(69)$ & $7(54)$ & $18(38)^{\mathrm{b}}$ & $0(0)$ \\
\hline Failed & $6(5)$ & $5(8)$ & $1(8)$ & $0(0)$ & $0(0)$ \\
\hline \multicolumn{6}{|l|}{ Adjuvant/first-line treatments } \\
\hline \multicolumn{6}{|l|}{ Complete lymph node dissection } \\
\hline Not performed & NA & NA & NA & $15(31)$ & NA \\
\hline
\end{tabular}


TABLE 1 continued

\begin{tabular}{|c|c|c|c|c|c|}
\hline \multirow{3}{*}{ Characteristics } & \multicolumn{5}{|l|}{$N(\%)$} \\
\hline & \multirow{2}{*}{$\begin{array}{l}\text { All patients } \\
N=133\end{array}$} & \multicolumn{4}{|c|}{ AJCC 8th edition stage at presentation } \\
\hline & & $\begin{array}{l}\text { Stage I } N=64 \\
(48 \%)\end{array}$ & $\begin{array}{l}\text { Stage II } N=13 \\
(10 \%)\end{array}$ & $\begin{array}{l}\text { Stage III } N=48 \\
(36 \%)\end{array}$ & $\begin{array}{l}\text { Stage IV } N=8 \\
(6 \%)\end{array}$ \\
\hline For positive SLNB & NA & NA & NA & $11(23)$ & NA \\
\hline For clinical nodal disease & NA & NA & NA & $22(46)$ & NA \\
\hline Primary tumor radiation & $46(35)$ & $18(28)$ & $5(38)$ & $23(48)$ & $0(0)$ \\
\hline Regional nodal basin radiation & $37(28)$ & $2(3)$ & $1(8)$ & $32(67)$ & $2(25)$ \\
\hline \multicolumn{6}{|l|}{ Chemotherapy } \\
\hline None & $116(87)$ & $64(100)$ & $13(100)$ & $34(71)$ & $5(62)$ \\
\hline Neoadjuvant & $2(2)$ & $0(0)$ & $0(0)$ & $2(4)$ & $0(0)$ \\
\hline Adjuvant & $10(8)$ & $0(0)$ & $0(0)$ & $10(21)$ & $0(0)$ \\
\hline Definitive treatment ${ }^{\mathrm{c}}$ & $5(4)$ & $0(0)$ & $0(0)$ & $2(4)$ & $3(38)$ \\
\hline \multicolumn{6}{|l|}{ Immunotherapy } \\
\hline None & $126(95)$ & $63(98)$ & $13(100)$ & $46(96)$ & $4(50)$ \\
\hline Pembrolizumab & $4(3)$ & $1(2)$ & $0(0)$ & $1(2)$ & $2(25)$ \\
\hline Avelumab & $3(2)$ & $0(0)$ & $0(0)$ & $1(2)$ & $2(25)$ \\
\hline
\end{tabular}

SLNB sentinel lymph node biopsy, AJCC American Joint Committee on Cancer, IQR interquartile range, CT computed tomography, PET/CT positron emission tomography/computed tomography, $N A$ not applicable

${ }^{a}$ Patients were staged based on clinically evident nodal or in-transit metastases and did not undergo SLNB

${ }^{\mathrm{b}}$ Seventeen patients had a positive SLNB. One patient had evidence of in-transit disease and was clinical stage III

${ }^{c}$ Patients did not undergo surgical resection

evident nodal or in-transit disease, and $17(35 \%)$ had microscopic metastases diagnosed by SLNB.

In total, $46(35 \%)$ of patients received primary tumor irradiation. Frequency of primary tumor radiation therapy increased with increasing AJCC stage from I (28\%) to III (48\%). Regional lymph node basin radiation therapy was utilized in $32(67 \%)$ patients who presented with stage III and $2(25 \%)$ with stage IV MCC. Receipt of chemotherapy was uncommon in only $17(14 \%)$ patients and limited to those with regional or distant metastases at disease presentation.

A total of 117 patients underwent baseline cross-sectional imaging (CT or PET/CT). Of these, $30(26 \%)$ patients had regional and $8(7 \%)$ had distant metastases. Only $2(2 \%)$ patients had isolated distant metastases without concurrent regional disease on imaging.

\section{First Metastatic Event}

The median follow-up time for patients who remained alive was 36 (IQR 20-66) months. In addition to the 56 patients who presented with stage III or IV MCC, another 22 patients developed regional or distant metastases during the follow-up period, for a total of $78(59 \%)$ patients with disease spread. The first site of metastasis was regional in $87 \%$ of patients, including $73 \%$ limited to the regional LN

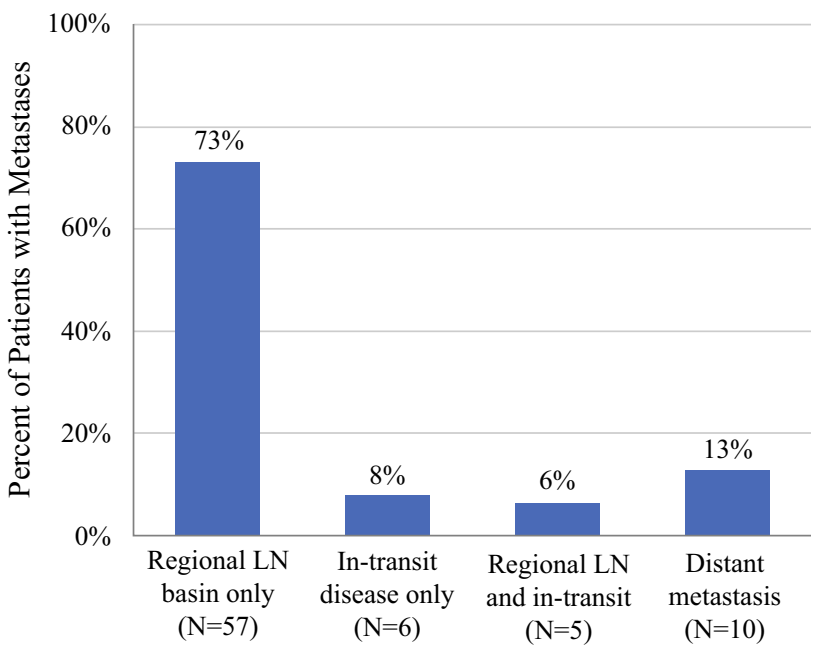

FIG. 1 First site of metastasis among 78 patients who developed regional or distant metastases. $L N$ lymph node

basin, $8 \%$ with in-transit disease only, and $6 \%$ with both nodal and in-transit disease (Fig. 1). Only $13 \%$ of patients had distant disease spread as the first metastatic event.

The first site of recurrence was additionally characterized among patients who underwent full pathologic staging at the time of disease diagnosis. Of the 51 patients who had a negative SLNB (pathologic stage I/II), 11 (22\%) 
subsequently developed regional-first recurrence. Five patients recurred within the regional $\mathrm{LN}$ basin first for a SLNB false negative rate of $22 \%$ [ 5 false negative/(5 false negative +18 true positive)]. Three $(60 \%)$ of these five patients had a head/neck primary. Six additional patients recurred with in-transit disease. Distant-first metastasis was rare in the SLNB-negative population and occurred for only one (2\%) patient.

Among the 48 patients who presented with either microscopic (diagnosed by SLNB) or clinically evident stage III MCC, $16(33 \%)$ recurred. The first site of recurrence in these pathologically staged patients was in-transit in four $(25 \%)$, concurrent in-transit and distant disease in three (19\%), and distant metastases in nine (56\%) patients.

\section{First Distant Metastasis and Distant Metastasis-Free Survival}

A total of 37 (28\%) patients eventually developed distant metastases, including 8 patients on presentation and 29 during the follow-up period. The most common first sites of distant metastasis were the abdominal viscera (51\%) and distant LNs (46\%) (Fig. 2). The lung (0\%) and brain (3\%) were rarely the first distant sites.

Among patients who initially presented with stage I through III MCC and subsequently developed distant disease $(N=29), 40 \%$ metastasized within 1 year of MCC diagnosis, $73 \%$ within 3 years, and $100 \%$ within 5 years. Unadjusted DMFS curves in these patients did not differ significantly by stage (log-rank $P=0.13$; Fig. 3 ). The 5-year DMFS rates were $71.2 \%$ (95\% confidence interval [CI] $56.0-90.4 \%)$ for stage I, $61.4 \% \quad(95 \%$ CI $32.7-100.0 \%)$ for stage II, and $61.6 \% \quad(95 \%$ CI

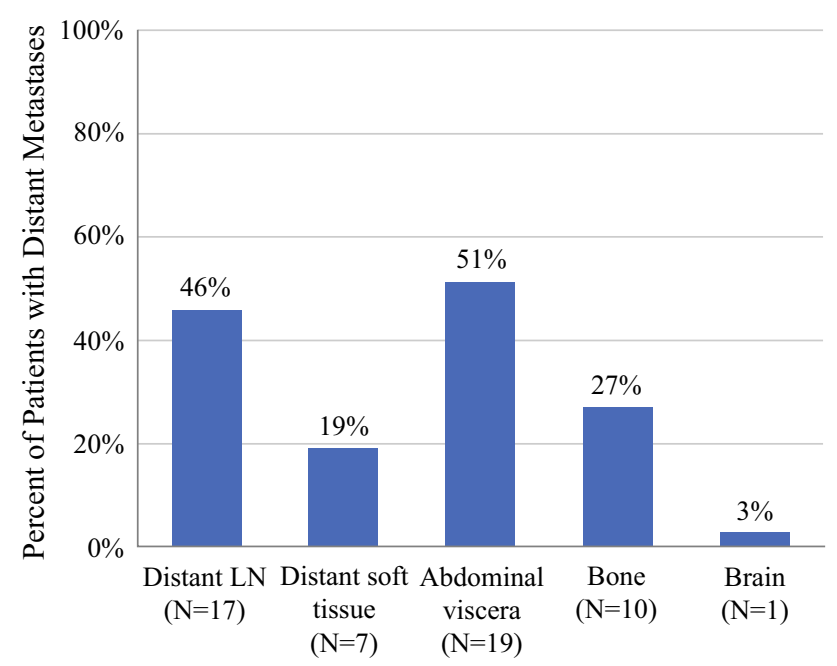

FIG. 2 First site(s) of distant metastasis among 37 patients who developed distant disease. $L N$ lymph node. Percentages do not add up to $100 \%$ as patients may have had multiple sites involved
47.4-80.0\%) for stage III patients. Median DMFS time had not been reached in any group. By multivariable Cox regression analysis, presentation with stage III disease was significantly associated with worse DMFS (stage III vs. I, hazard ratio $[\mathrm{HR}] 4.87,95 \% \mathrm{CI} 1.84-12.9, P=0.001$; Table 2). Additionally, DMFS decreased with increasing age (HR $1.05,95 \%$ CI $1.01-1.09, P=0.018$ ), whereas an unknown primary tumor location (HR $0.18,95 \%$ CI $0.04-0.91, P=0.038$ ) and irradiation of the primary tumor (HR $0.24,95 \%$ CI $0.09-0.65, P=0.005$ ) were associated with improved DMFS.

\section{Merkel Cell-Specific Survival}

The overall 5-year MSS rate for the study cohort was $71.9 \%$ (95\% CI 62.9-82.1\%). The MSS curves differed significantly by stage at presentation (log-rank $P<0.001$ ) (Fig. 4). In particular, patients with stage IV MCC at presentation experienced substantially worse survival with a 5-year MSS rate of only 25.0\% (95\% CI 7.5-83.0\%). Presentation with stage IV disease remained associated with worse MSS by multivariable analysis (stage IV vs. I, HR $6.30,95 \%$ CI 1.93-20.5, $P=0.002$; Table 3). Primary tumor excision margin was associated with MSS by univariate analysis, but not after adjusting for AJCC stage, and was therefore not included in the final multivariable regression. Patients who received primary tumor radiation therapy experienced improved MSS (HR 0.23, 95\% CI $0.08-0.71, P=0.011)$.

\section{DISCUSSION}

MCC is an uncommon but aggressive cutaneous neuroendocrine malignancy. Because of the relative infrequency of this disease, the patterns of metastasis in MCC have not been adequately evaluated. In the current study, the regional LN basin was confirmed as a frequent first site of metastasis, preceding the development of distant disease. Distant metastasis, however, was common and developed in nearly one-third of study patients. MCC appears to have a predilection for certain sites, with the abdominal viscera and distant LNs frequently representing the first distant sites of disease.

Among patients who developed disease spread in the current study, $73 \%$ had isolated regional nodal involvement as the first metastatic event. The early and high rate of regional $\mathrm{LN}$ basin metastasis confirms the importance of SLNB for patients with clinically localized MCC. The SLN positivity rate was $25 \%$, consistent with the range reported in the literature for MCC (23-45\%) and comparable to that for thick melanoma (26-33\%), for which SLNB is typically recommended. ${ }^{8,10,11,16-27}$ Frequent regional LN 


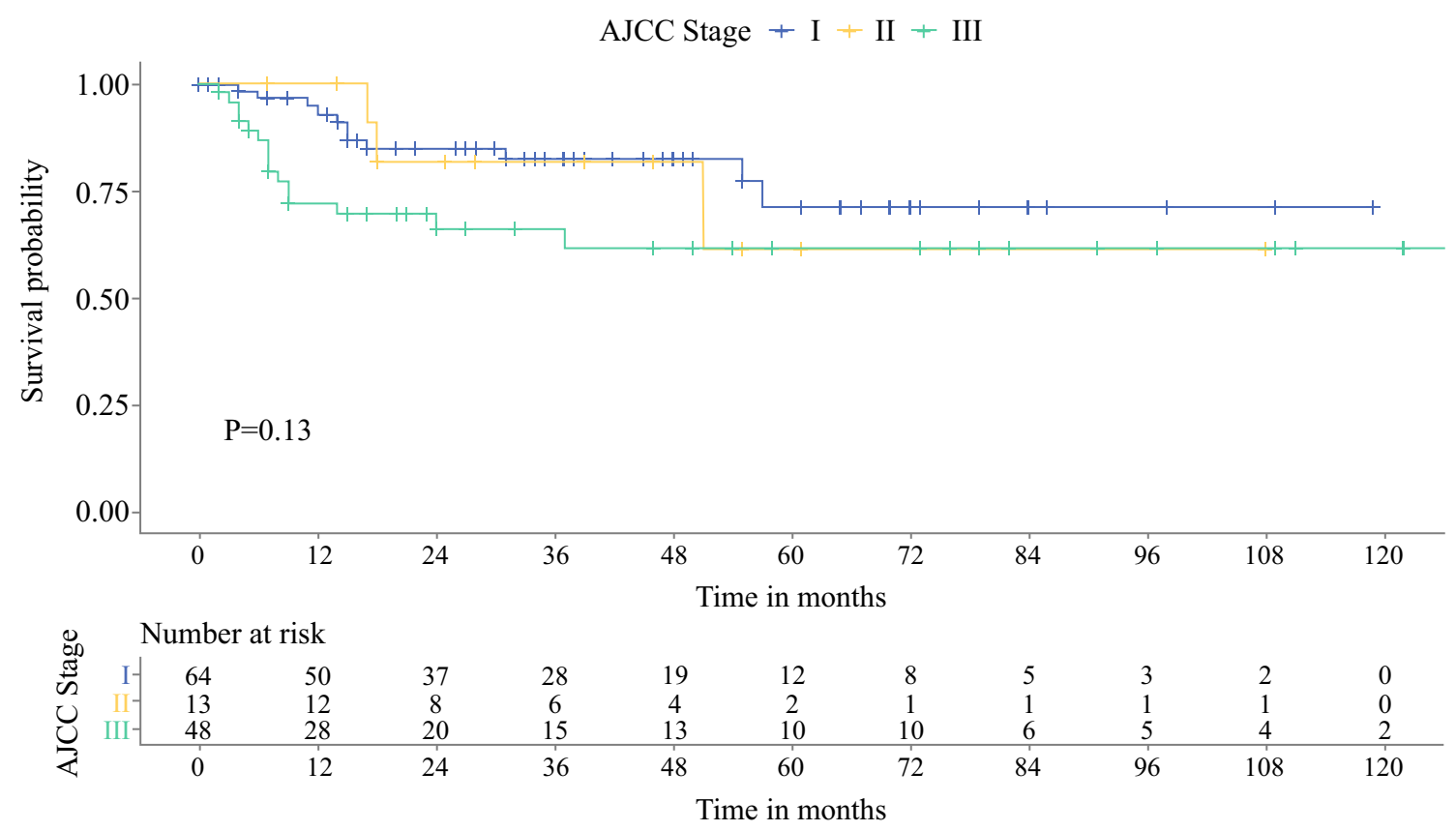

FIG. 3 Kaplan-Meier estimates of distant metastasis-free survival of 125 patients who presented with American Joint Committee on Cancer (AJCC) stage I through III Merkel cell carcinoma

surveillance following initial MCC treatment also should be prioritized. The false-negative rate for SLNB was relatively high at $22 \%$ in the present study and in the range of $15-21 \%$ in the literature. ${ }^{8,28-30}$

Accurate pathologic staging also could inform risk of distant disease recurrence. Distant-first recurrence was very rare in the SLNB-negative population (pathologic stage I/II), occurring in only one patient, but developed in $56 \%$ of patients with stage III MCC who subsequently relapsed. Furthermore, on baseline imaging, only $2 \%$ of patients had isolated distant disease without regional nodal involvement, and a minority (13\%) of all study patients had distant disease spread as the first metastatic event. These findings suggest that regional LN metastasis likely precedes distant metastasis in a majority of patients. Lymphovascular invasion may be an early occurrence in MCC, present in $90 \%$ of primary tumor samples in one study, while isolated blood vascular invasion is much less common in only $3 \% .^{31}$ By identifying regional nodal metastases early, appropriate treatments could be offered in a timely manner to perhaps prevent distant disease relapse. ${ }^{10,19}$

Additionally, the presence of LN metastases at the time of MCC presentation was associated with significantly worse DMFS, whereas resection margin of the primary tumor was not associated with either DMFS or MSS, consistent with recent findings by Perez et al. ${ }^{32}$ It may be appropriate to choose a feasible margin of excision without compromising necessary adjuvant treatments, as recommended by national practice guidelines. ${ }^{7}$ In the current study, primary tumor radiation therapy also was associated with improved DMFS and MSS, consistent with findings from a multicenter study that demonstrated improved locoregional disease control, DMFS, and MSS among patients with MCC who received adjuvant primary tumor radiation. $^{33}$

Distant LNs and intra-abdominal organs were most often the first sites of distant metastases in the present study, consistent with previous findings that these sites are frequently involved in metastatic MCC. ${ }^{12,13,34}$ While we found that the lung $(0 \%)$ and brain $(3 \%)$ were rarely the first sites of distant spread, they may be subsequently involved in $30 \%$ and $13 \%$ of patients, respectively. ${ }^{34}$ Understanding these patterns of metastasis may help to guide follow-up imaging strategies. For example, chest and abdominopelvic imaging, especially in patients who already have regional LN involvement, should be routinely performed for restaging, whereas dedicated brain imaging may be reserved for patients who demonstrate concerning signs and symptoms.

Among patients who initially presented with stage I through III MCC, median DMFS time had not been reached after a median follow-up time of 36 months in the study cohort. Kouzmina et al. reported that the longest latency period between diagnosis and distant metastasis was 14.2 years, but the median time to distant disease was 2.5 years among patients who did not present with stage IV 
TABLE 2 Characteristics associated with distant metastasis-free survival among patients who presented with American Joint Committee on Cancer (AJCC) stage I through III Merkel cell carcinoma

\begin{tabular}{|c|c|c|c|c|}
\hline Characteristic & Univariate OR (95\% CI) & $P$ value & Multivariable OR (95\% CI) & $P$ value \\
\hline \multicolumn{5}{|l|}{ AJCC stage at presentation } \\
\hline Stage I & Reference & & Reference & \\
\hline Stage II & $1.19(0.33-4.28)$ & 0.79 & $0.99(0.27-3.67)$ & 0.99 \\
\hline Stage III & $2.15(0.99-4.68)$ & 0.055 & $4.87(1.84-12.9)$ & 0.001 \\
\hline Age, per year & $1.04(1.00-1.08)$ & 0.026 & $1.05(1.01-1.09)$ & 0.018 \\
\hline \multicolumn{5}{|l|}{ Sex } \\
\hline Female & Reference & & & \\
\hline Male & $2.12(0.90-4.99)$ & 0.084 & & \\
\hline Immunosuppression & $1.33(0.46-3.84)$ & 0.59 & & \\
\hline Previous malignancy & $1.43(0.67-3.02)$ & 0.35 & & \\
\hline \multicolumn{5}{|l|}{ Primary tumor location } \\
\hline Head/neck & Reference & & Reference & \\
\hline Upper extremity & $0.32(0.09-1.10)$ & 0.070 & $0.68(0.18-2.49)$ & 0.56 \\
\hline Lower extremity & $0.97(0.39-2.41)$ & 0.95 & $1.14(0.44-2.95)$ & 0.79 \\
\hline Trunk & $1.03(0.30-3.59)$ & 0.96 & $1.11(0.30-4.08)$ & 0.88 \\
\hline Unknown primary/not reported & $0.66(0.15-2.90)$ & 0.58 & $0.18(0.04-0.91)$ & 0.038 \\
\hline \multicolumn{5}{|l|}{ Presence of lymphovascular invasion } \\
\hline Absent & Reference & & & \\
\hline Present & $1.84(0.70-4.84)$ & 0.094 & & \\
\hline Unknown primary/not reported & $1.84(0.70-4.84)$ & 0.22 & & \\
\hline \multicolumn{5}{|l|}{ Primary tumor depth (mm) } \\
\hline$\leq 6.0$ & Reference & & & \\
\hline$>6.0$ & $1.70(0.73-3.99)$ & 0.22 & & \\
\hline Unknown primary/not reported & $0.80(0.30-2.14)$ & 0.65 & & \\
\hline \multicolumn{5}{|l|}{ Primary tumor excision margin $(\mathrm{cm})$} \\
\hline No excision & Reference & & & \\
\hline$\leq 0.5$ & $0.32(0.06-1.76)$ & 0.19 & & \\
\hline$>0.5-1.0$ & $0.83(0.22-3.12)$ & 0.79 & & \\
\hline$>1.0-2.0$ & $0.71(0.22-2.30)$ & 0.56 & & \\
\hline$>2.0$ & $0.89(0.10-8.01)$ & 0.92 & & \\
\hline Not reported & $1.20(0.36-4.01)$ & 0.76 & & \\
\hline \multicolumn{5}{|l|}{ Complete lymph node dissection } \\
\hline Not performed & Reference & & & \\
\hline Performed & $3.73(1.73-8.05)$ & $<0.001$ & & \\
\hline Primary tumor radiation & $0.43(0.18-1.02)$ & 0.054 & $0.24(0.09-0.65)$ & 0.005 \\
\hline Regional nodal basin radiation & $0.91(0.40-2.06)$ & 0.83 & & \\
\hline \multicolumn{5}{|l|}{ Chemotherapy } \\
\hline None & Reference & & & \\
\hline Neoadjuvant & $3.90(0.51-29.9)$ & 0.19 & & \\
\hline Adjuvant & $0.66(0.16-2.79)$ & 0.57 & & \\
\hline
\end{tabular}

$O R$ odds ratio, $C I$ confidence interval

MCC. ${ }^{34}$ All distant metastases in the present study occurred within the first 5 years. Similarly, Lewis et al. found that $99 \%$ of distant disease spread occurred within 5 years of initial MCC diagnosis. ${ }^{13}$ These data support active surveillance during the early years following MCC diagnosis. $^{12}$ 
AJCC Stage + I + II + III + IV

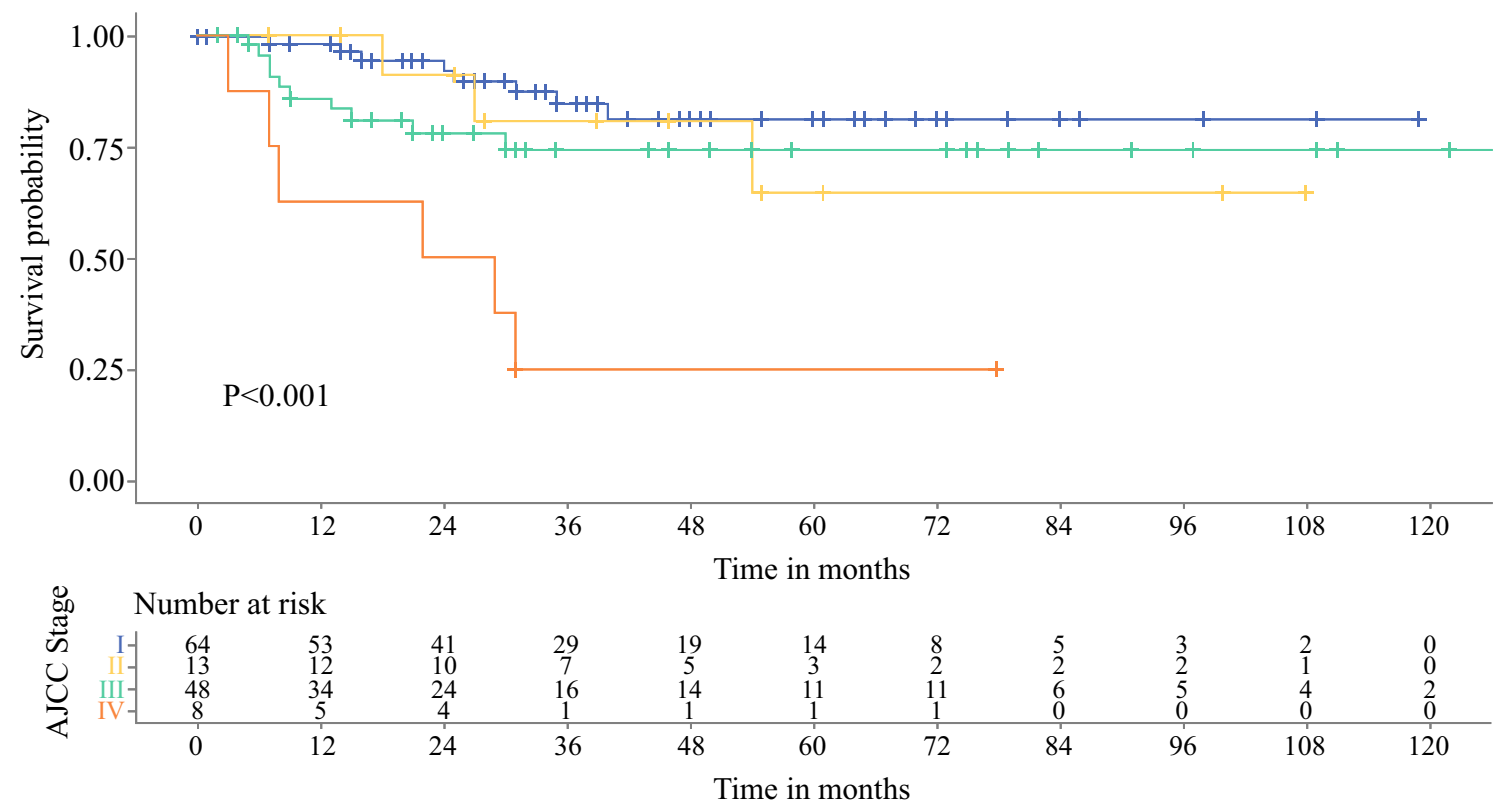

FIG. 4 Kaplan-Meier estimates of Merkel cell-specific survival

With respect to baseline and follow-up imaging modalities, PET/CT may be superior to CT in identifying distant involvement in MCC. PET/CT was the most common baseline imaging modality utilized in $68 \%$ of our study patients. In a small study of 18 patients with MCC, Concannon et al. found that PET/CT altered staging for 7 $(33 \%)$ and changed management for $9(43 \%)$ patients. Hawryluk et al. reported that PET/CT upstaged $16 \%$ of patients who underwent baseline scans at presentation of MCC. ${ }^{12}$ In contrast, CT appears to have high sensitivity for distant MCC spread (100\%), but very poor specificity $(48 \%) .^{10}$

Limitations of the current study include its retrospective nature and moderately sized cohort. While multivariable analyses adjusted for some covariates, these could not account for unobserved or unrecorded differences between patient groups. Patients classified as stage I and II may have represented a relatively heterogeneous population, because not all of these patients were pathologically staged, which could partially explain the absence of a significant difference in DMFS and MSS between these groups. Preliminary subgroup analyses of disease recurrence patterns among patients who were pathologically staged were presented here and will be further validated in a multicenter study. Additionally, patients received variable treatments, the heterogeneity of which may not be fully accounted for in the analyses of recurrence and survival outcomes. Finally, there may be a referral bias to an academic center of patients with more advanced disease or complex comorbidities, which could affect the generalizability of our findings.

\section{CONCLUSIONS}

The regional $\mathrm{LN}$ basin is the most common first metastatic site in MCC, confirming the importance of nodal evaluation at the time of diagnosis. Certain sites, including the abdominal viscera and distant LNs, are frequently involved early in distant metastatic disease, whereas the lung and brain were rarely the first distant sites. Recognizing these patterns of metastasis could help to guide surveillance strategies, which may focus on nodal disease for patients confirmed to have stage I and II MCC and include routine cross-sectional imaging for those who have had regional disease spread. A multicenter, retrospective study is planned to further validate these patterns of metastasis and to identify optimal surveillance strategies for patients diagnosed with MCC. 
TABLE 3 Characteristics associated with Merkel cell-specific survival

\begin{tabular}{|c|c|c|c|c|}
\hline Characteristic & Univariate OR (95\% CI) & $P$ value & Multivariable OR $(95 \% \mathrm{CI})$ & $P$ value \\
\hline \multicolumn{5}{|c|}{ American Joint Committee on Cancer stage at presentation } \\
\hline Stage I & Reference & & Reference & \\
\hline Stage II & $1.65(0.44-6.21)$ & 0.46 & $1.26(0.33-4.85)$ & 0.74 \\
\hline Stage III & $1.93(0.76-4.88)$ & 0.17 & $2.27(0.80-6.42)$ & 0.12 \\
\hline Stage IV & $7.71(2.66-22.3)$ & $<0.001$ & $6.30(1.93-20.5)$ & 0.002 \\
\hline Age, per year & $1.03(0.99-1.06)$ & 0.15 & & \\
\hline \multicolumn{5}{|l|}{ Sex } \\
\hline Female & Reference & & & \\
\hline Male & $1.47(0.64-3.37)$ & 0.36 & & \\
\hline Immunosuppression & $2.35(0.94-5.82)$ & 0.066 & $2.70(0.98-7.44)$ & 0.056 \\
\hline Previous malignancy & $0.65(0.26-1.62)$ & 0.36 & & \\
\hline \multicolumn{5}{|l|}{ Primary tumor location } \\
\hline Head/neck & Reference & & & \\
\hline Upper extremity & $0.38(0.08-1.79)$ & 0.22 & & \\
\hline Lower extremity & $2.07(0.80-5.38)$ & 0.13 & & \\
\hline Trunk & $1.61(0.43-6.07)$ & 0.48 & & \\
\hline Unknown primary/not reported & $2.38(0.78-7.29)$ & 0.13 & & \\
\hline \multicolumn{5}{|l|}{ Primary tumor depth (mm) } \\
\hline$\leq 6.0$ & Reference & & & \\
\hline$>6.0$ & $1.46(0.57-3.70)$ & 0.43 & & \\
\hline Unknown primary/not reported & $1.06(0.41-2.74)$ & 0.91 & & \\
\hline \multicolumn{5}{|c|}{ Presence of lymphovascular invasion } \\
\hline Absent & Reference & & Reference & \\
\hline Present & $2.59(0.97-6.91)$ & 0.058 & $2.55(0.92-7.04)$ & 0.072 \\
\hline Unknown primary/not reported & $1.70(0.60-4.77)$ & 0.32 & $0.96(0.29-3.15)$ & 0.95 \\
\hline \multicolumn{5}{|l|}{ Primary tumor excision margin $(\mathrm{cm})$} \\
\hline No excision & Reference & & & \\
\hline$\leq 0.5$ & $0.11(0.01-0.86)$ & 0.035 & & \\
\hline$>0.5-1.0$ & $0.58(0.19-1.75)$ & 0.34 & & \\
\hline$>1.0-2.0$ & $0.31(0.11-0.86)$ & 0.025 & & \\
\hline$>2.0$ & $0.54(0.07-4.28)$ & 0.56 & & \\
\hline Not reported & $0.51(0.17-1.54)$ & 0.23 & & \\
\hline \multicolumn{5}{|l|}{ Complete lymph node dissection } \\
\hline Not performed & Reference & & & \\
\hline Performed & $1.77(0.83-3.77)$ & 0.14 & & \\
\hline Primary tumor radiation & $0.27(0.09-0.79)$ & 0.017 & $0.23(0.08-0.71)$ & 0.011 \\
\hline Regional nodal basin radiation & $0.71(0.28-1.75)$ & 0.45 & & \\
\hline \multicolumn{5}{|l|}{ Chemotherapy } \\
\hline None & Reference & & & \\
\hline Neoadjuvant & $4.39(0.57-33.5)$ & 0.15 & & \\
\hline Adjuvant & $0.41(0.06-3.03)$ & 0.38 & & \\
\hline Definitive treatment ${ }^{\mathrm{a}}$ & $1.71(0.40-7.28)$ & 0.47 & & \\
\hline
\end{tabular}

$O R$ odds ratio, $C I$ confidence interval

${ }^{\mathrm{a}}$ Patients did not undergo surgical resection 
FUNDING No external funding was received for this study.

DISCLOSURES The authors declare no relevant conflict of interest.

\section{REFERENCES}

1. Toker C. Trabecular carcinoma of the skin. Arch Dermatol. 1972;105(1):107-10.

2. Rollison DE, Giuliano AR, Becker JC. New virus associated with Merkel cell carcinoma development. J Natl Compr Cancer Netw. 2010;8(8):874-80. https://doi.org/10.6004/jnccn.2010.0064

3. Tarantola TI, Vallow LA, Halyard MY, et al. Prognostic factors in Merkel cell carcinoma: analysis of 240 cases. J Am Acad Dermatol. 2013;68(3):425-32. https://doi.org/10.1016/j.jaad.201 2.09.036

4. Becker JC, Strang A, DeCaprio JA, et al. Merkel cell carcinoma. Nat Rev Dis Primers. 2017;3:17077. https://doi.org/10.1038/nrdp. 2017.77

5. Paulson KG, Park SY, Vandeven NA, et al. Merkel cell carcinoma: current U.S. incidence and projected increases based on changing demographics. $J \mathrm{Am}$ Acad Dermatol. 2018;78(3):457-632. https://doi.org/10.1016/j.jaad.2017.10.028

6. Harms KL, Healy MA, Nghiem P, et al. Analysis of prognostic factors from 9387 Merkel cell carcinoma cases forms the basis for the new 8th edition AJCC staging system. Ann Surg Oncol. 2016;23(11):3564-71. https://doi.org/10.1245/s10434-016-52664

7. Schmults CD, Blitzblau R, Aasi SZ, et al. NCCN clinical practice guidelines in oncology: Merkel cell carcinoma (version 2.2019). 2019. https://www.nccn.org/professionals/physician_gls/default.a spx. Accessed 1 Sept 2019.

8. Fields RC, Busam KJ, Chou JF, et al. Recurrence and survival in patients undergoing sentinel lymph node biopsy for merkel cell carcinoma: analysis of 153 patients from a single institution. Ann Surg Oncol. 2011;18(9):2529-37. https://doi.org/10.1245/s1043 4-011-1662-y

9. Fritsch VA, Camp ER, Lentsch EJ. Sentinel lymph node status in Merkel cell carcinoma of the head and neck: not a predictor of survival. Head Neck. 2014;36(4):571-9. https://doi.org/10.1002/ hed.23334

10. Gupta SG, Wang LC, Penas PF, Gellenthin M, Lee SJ, Nghiem P. Sentinel lymph node biopsy for evaluation and treatment of patients with Merkel cell carcinoma: the Dana-Farber experience and meta-analysis of the literature. Arch Dermatol. 2006;142(6):685-90. https://doi.org/10.1001/archderm.142.6.685

11. Conic RRZ, Ko J, Damiani G, et al. Predictors of sentinel lymph node positivity in thin melanoma using the National Cancer Database. J Am Acad Dermatol. 2019;80(2):441-7. https://doi. org/10.1016/j.jaad.2018.08.051

12. Hawryluk EB, O'Regan KN, Sheehy N, et al. Positron emission tomography/computed tomography imaging in Merkel cell carcinoma: a study of 270 scans in 97 patients at the Dana-Farber/ Brigham and Women's Cancer Center. J Am Acad Dermatol. 2013;68(4):592-9. https://doi.org/10.1016/j.jaad.2012.08.042

13. Lewis CW, Qazi J, Hippe DS, et al. Patterns of distant metastases in 215 Merkel cell carcinoma patients: implications for prognosis and surveillance. Cancer Med. 2019. https://doi.org/10.1002/ca $\mathrm{m} 4.2781$

14. Amin M, Edge S, Greene F. Merkel cell carcinoma (Chapter 46). In: American joint committee on cancer staging manual, 8th edn. Switzerland: Springer; 2017. pp 549-61.

15. R Core Team. R: A language and environment for statistical computing. R Foundation for Statistical Computing, Vienna,
Austria. https://www.R-project.org/. Published 2019. Accessed 1 July 2019.

16. Allen PJ, Bowne WB, Jaques DP, Brennan MF, Busam K, Coit DG. Merkel cell carcinoma: prognosis and treatment of patients from a single institution. J Clin Oncol. 2005;23(10):2300-9. h ttps://doi.org/10.1200/jco.2005.02.329

17. Schwartz JL, Griffith KA, Lowe L, et al. Features predicting sentinel lymph node positivity in Merkel cell carcinoma. J Clin Oncol. 2011;29(8):1036-41. https://doi.org/10.1200/jco.2010.33. 4136

18. Santamaria-Barria JA, Boland GM, Yeap BY, Nardi V, DiasSantagata D, Cusack JC. Merkel cell carcinoma: 30-year experience from a single institution. Ann Surg Oncol. 2013;20(4):1365-73. https://doi.org/10.1245/s10434-012-2779-3

19. Asgari MM, Sokil MM, Warton EM, Iyer J, Paulson KG, Nghiem P. Effect of host, tumor, diagnostic, and treatment variables on outcomes in a large cohort with Merkel cell carcinoma. JAMA Dermatol. 2014;150(7):716-23. https://doi.org/10.1001/jamader matol.2013.8116

20. Smith FO, Yue B, Marzban SS, et al. Both tumor depth and diameter are predictive of sentinel lymph node status and survival in Merkel cell carcinoma. Cancer. 2015;121(18):3252-60. http s://doi.org/10.1002/cncr.29452

21. Sims JR, Grotz TE, Pockaj BA, et al. Sentinel lymph node biopsy in Merkel cell carcinoma: the Mayo Clinic experience of 150 patients. Surg Oncol. 2018;27(1):11-7. https://doi.org/10.1016/j. suronc.2017.10.005

22. Ferrone CR, Panageas KS, Busam K, Brady MS, Coit DG. Multivariate prognostic model for patients with thick cutaneous melanoma: importance of sentinel lymph node status. Ann Surg Oncol. 2002;9(7):637-45.

23. Morton DL, Thompson JF, Cochran AJ, et al. Final trial report of sentinel-node biopsy versus nodal observation in melanoma. $N$ Engl J Med. 2014;370(7):599-609. https://doi.org/10.1056/nejm oa1310460

24. Kachare SD, Singla P, Vohra NA, Zervos EE, Wong JH, Fitzgerald TL. Sentinel lymph node biopsy is prognostic but not therapeutic for thick melanoma. Surgery. 2015;158(3):662-8. h ttps://doi.org/10.1016/j.surg.2015.05.012

25. Bello DM, Han G, Jackson L, et al. The prognostic significance of sentinel lymph node status for patients with thick melanoma. Ann Surg Oncol. 2016;23(5):938-45. https://doi.org/10.1245/s10434016-5502-y

26. Song Y, Azari FS, Metzger DA, Fraker DL, Karakousis GC. Practice patterns and prognostic value of sentinel lymph node biopsy for thick melanoma: a National Cancer Database study. Ann Surg Oncol. 2019;26(13):4651-62. https://doi.org/10.1245/ s10434-019-07783-0

27. Coit DG, Thompson JF, Albertini MR, et al. NCCN clinical practice guidelines in oncology: cutaneous melanoma (version 2.2019). 2019. https://www.nccn.org/professionals/physician_gl s/default.aspx. Accessed 15 Mar 2019.

28. Gunaratne DA, Howle JR, Veness MJ. Sentinel lymph node biopsy in Merkel cell carcinoma: a 15-year institutional experience and statistical analysis of 721 reported cases. Br J Dermatol. 2016;174(2):273-81. https://doi.org/10.1111/bjd.14240

29. Jouary T, Kubica E, Dalle S, et al. Sentinel node status and immunosuppression: recurrence factors in localized Merkel cell carcinoma. Acta Derm Venereol. 2015;95(7):835-40. https://doi. org/10.2340/00015555-2099

30. Karunaratne YG, Gunaratne DA, Veness MJ. Systematic review of sentinel lymph node biopsy in Merkel cell carcinoma of the head and neck. Head Neck. 2018;40(12):2704-13. https://doi.org/ 10.1002/hed.25345

31. Kukko HM, Koljonen VSK, Tukiainen EJ, Haglund CH, Bohling TO. Vascular invasion is an early event in pathogenesis of Merkel 
cell carcinoma. Mod Pathol. 2010;23(8):1151-6. https://doi.org/ 10.1038/modpathol.2010.100

32. Perez MC, de Pinho FR, Holstein A, et al. Resection margins in Merkel cell carcinoma: is a 1-cm margin wide enough? Ann Surg Oncol. 2018;25(11):3334-40. https://doi.org/10.1245/s10434-01 8-6688-y

33. Ghadjar P, Kaanders JH, Poortmans P, et al. The essential role of radiotherapy in the treatment of Merkel cell carcinoma: a study from the Rare Cancer Network. Int J Radiat Oncol Biol Phys. 2011;81(4):e583-91. https://doi.org/10.1016/j.ijrobp.2011.05.028
34. Kouzmina M, Koljonen V, Leikola J, Böhling T, Lantto E. Frequency and locations of systemic metastases in Merkel cell carcinoma by imaging. Acta Radiol Open. 2017. https://doi.org/ $10.1177 / 2058460117700449$

Publisher's Note Springer Nature remains neutral with regard to jurisdictional claims in published maps and institutional affiliations. 